\title{
O Despertar Do Gigante: Reflexões Sobre O Poder De Agenda Do Presidente Em Períodos De Crise.
}

The Awakening Of The Giant: Reflexions On President's Power Of Agenda During Crisis.

Iani Panait ${ }^{1}$

Robert George Otoni de Melo²

\section{RESUMO}

O presente artigo objetiva compreender a correlação de forças entre os poderes Executivo e Legislativo em momentos históricos de engessamento da vida política no país. Em períodos caracterizados por crise econômica e/ou política, a instabilidade da agenda pública leva à prevalência do Executivo Federal, em detrimento das discussões no seio do parlamento brasileiro, gerando certa instabilidade e agravando períodos de abalo institucional. Através do método qualitativo, o artigo revisará bibliografia para analisar a hipótese de hegemonia da agenda da Presidência da República em relação aos outros poderes, inclusive, através de seus mecanismos de veto, visando pautar o jogo político.

PALAVRAS-CHAVE: Poder de agenda; Predominância do Executivo; Medida provisória; Decreto-lei; Gestão de crises.

\begin{abstract}
This paper aims to understand the correlation of forces between the Executive and Legislative powers in historical moments of political life in the country. In periods characterized by economic and/or political crisis, the instability of the public agenda leads to the prevalence of the Federal Executive, to the detriment of discussions within the Brazilian parliament, generating certain instability and aggravating periods of institutional upheaval. Through the qualitative method, the article will review the bibliography to analyse the hypothesis of the hegemony of the Presidency of the Republic's agenda in relation to other powers, including, through its veto mechanisms, aiming to guide the political game.
\end{abstract}

KEY-WORDS: Power of agenda; Predominance of the Executive; Provisional measure; Decreelaw; crisis management.

\footnotetext{
1 Doutorando em Direito (Ciências Jurídico-Políticas) pela Universidade de Lisboa. Mestre em Ciências Sociais pela Pontifícia Universidade Católica do Rio de Janeiro. Graduado em Direito pela Universidade Federal Fluminense. 2 Mestre em Direito e Desenvolvimento pela Escola de Direito da Fundação Getúlio Vargas. Graduado em Direito pela Pontifícia Universidade Católica de São Paulo.
} 


\section{INTRODUÇÃO}

Neste artigo, propõe-se discutir as formas pelas quais o poder executivo federal, na figura do Presidente da República, gerenciou as crises político-econômicas em diferentes momentos da história do país. Através dos instrumentos formais estabelecidos, sugere-se que o Executivo utilizou-lhes para garantir a predominância de uma agenda própria - e de interesse do Executivo nos momentos conhecidos como os de "crises político-econômica". Por crise, entende-se aqui o conceito de Pearson (1998) segundo o qual é possível observar uma crise sob três eixos: uma perspectiva técnica e meramente estrutural, uma perspectiva psicológica e uma perspectiva sóciopolítica. Evidentemente, interessa a este artigo compreender uma crise sob o enfoque sóciopolítico, sobretudo, por se considerar uma quebra do sentido partilhado de vida coletiva e social verificando-se uma mudança marginal nas condições vida material e política (MENDES, 2005, p. 1).

Os estudos sobre a predominância do poder Executivo não são particularmente novos no contexto acadêmico brasileiro (PEREIRA; MUELLER, 2000), sendo que o interesse aqui está em compreender de que modo a reação de um poder constituído em um cenário de ruptura ou disrupção pode nos ajudar a observar melhor um aspecto importante de um campo de estudos pertinente: a atuação do poder ${ }^{3}$.

Desse modo, em um primeiro momento, o artigo discutirá quais são formas instrumentais utilizadas pelo poder executivo federal brasileiro no contexto republicano para lidar com as crises políticas discriminadas. Em um segundo momento, sugere-se em quais momentos e em quais momentos tais instrumentos foram utilizados para gerir essas crises, sobretudo, como e em quais condições isso ocorreu no plano do mundo fenomênico. Em um terceiro momento, o artigo traz as conclusões sobre os achados submetendo-o ao debate acadêmico.

\section{CAIXA DE FERRAMENTAS: DECRETOS-LEI, MEDIDAS PROVISÓRIAS E OS VETOS PRESIDENCIAIS}

\footnotetext{
3 Para Robert Dahl (1957) poder político como uma influência sobre as ações dos outros, ou seja, quando 'A
} tem poder sobre B na medida em que ele pode fazer com que B faça algo que B não faria de outra maneira” (p. 202) 
Cadernos de Estudos Sociais e Políticos, Rio de Janeiro, vol. 6, 2018.

Em comum às várias crises, há um aspecto gerencial em todas elas. A hipótese de uma gestão dessas crises pode ser lida como uma tentativa do Executivo em controlar a ordem política e econômica através dos instrumentos arbitrados na Constituição. Os mecanismos políticos são variados, mas para este artigo destacam-se aqueles previstos nos textos constitucionais: os decretoslei, as medidas provisórias e os vetos presidenciais. Alguns previstos em Constituições, caso dos decretos-lei, previstos nos textos outorgados em períodos de exceção $(1937,1967,1969)$, outros previstos somente no texto promulgado (1988). Em todas, há a previsão expressa do veto presidencial.

A natureza desses instrumentos será explorada no bojo deste artigo. A princípio, convém destacar um conceito-chave na hipótese central do texto: o poder de agenda. A possibilidade de o poder executivo utilizar desses mecanismos para impor uma agenda pode ser uma forma possível de identificação e localização dos poderes do Executivo.

Uma visão possível para a origem de um poder de agenda no âmbito do poder executivo pode estar em Giddens (1974) ao apontar a intensa relação entre o poder decisório e elites impondo um binômio entre a 'relevância institucional' do aparelho e 'hierarquia' política entre os grupos políticos:

\footnotetext{
Ao determinar o predomínio relativo dos grupos de elite em termos da sua posse do poder, há dois fatores centrais que devem ser levados em consideração: vou me referir a eles como a natureza da hierarquia que existe entre grupos de elite e a relevância institucional das formas de organização social ou da instituição [política ou burocrática] que eles comandam. O primeiro fator está intimamente relacionado a um aspecto do poder indicado anteriormente: o grau de importância dos problemas chave controlados pelos grupos de elite. Existe uma hierarquia entre grupos de elite quando um grupo (por exemplo, a elite política) possui poder sobre questões mais decisivas do que aquelas determinadas por outros e, por isso, é capaz de exercer em grau maior ou menor um controle sobre esses últimos. A "relevância institucional" refere-se à dimensão vertical do poder: a idéia pode ser definida pelo grau em que uma dada instituição afeta as oportunidades de vida do conjunto de indivíduos que pertencem a ela (GUANDALI JR; CONDATO, 2016 apud GIDDENS, 1974, p. 8).
}

Neste contexto, o poder de agenda significaria a predominância dos interesses de um dado grupo político sobre outro, menos influente e mais escasso de recursos políticos e burocráticos, por exemplo. No limite, o grupo político inserido dentro do aparelho institucional tende a impor seu conjunto de interesses em detrimento dos outros grupos políticos. Parte dessa noção nos ajuda a compreender o papel funcional do poder Executivo enquanto ator inserido numa dada correlação de forças com os demais poderes da República considerando-se sua dimensão institucional como paradigma para a imposição de pautas próprias. 
Cadernos de Estudos Sociais e Políticos, Rio de Janeiro, vol. 6, 2018.

Discute-se, então, se esse poder de agenda teria inclinação motivada, particularmente, ao interesse geral do poder executivo ou não. Os debates em torno desse tema são numerosos, impondo até mesmo uma divisão entre aqueles que acreditam na baixa implementação em decorrência do conflito permanente entre os poderes legislativo e executivo e aqueles que acreditam na figura centralizadora do Executivo como predominante de seus interesses (DINIZ, 2005, p. 5).

De qualquer modo, interessa a esse artigo discutir em que aspecto a atuação do poder executivo buscou implementar uma agenda própria aproveitando-se de um dado quadro de crise político-econômica. Considerando os estudos de Mainwaring e Shugart (1997) pelo qual sistematizam a predominância dos poderes do Presidente da República em três eixos: (i) poderes proativos (caracterizado pela adoção de medidas provisórias) (ii) poderes reativos (caracterizado pelo veto presidencial) e poderes exclusivos (em que o Presidente pode pautar a agenda). A título de exemplo, de 805 propostas que tramitaram no Congresso Nacional do Brasil durante os períodos compreendidos em 1995 a 1998, "648 (80,49\%) foram iniciadas pelo Executivo, 141 (17,51\%) foram iniciadas pelo Legislativo e apenas 16 (1,98\%) pelo Judiciário" (PEREIRA; MUELLER, 2000, p. 47).

Veremos no artigo o exercício dessa predominância sustando sua projeção em momentos cruciais da vida política brasileira.

\section{DECRETOS-LEI}

Um dos primeiros instrumentos de centralização da atuação de poder foram os decretoslei. Com a vigência a partir da Constituição de 1937, os decretos-lei têm sua existência repetida em outras duas Constituições, a de 1967 e 1969, as três outorgadas por Presidentes durante regimes de exceção. $\mathrm{O}$ interesse por esse instrumento justifica-se não somente pelo seu uso largamente realizado (os decretos-lei totalizam, entre 1965 e 1988, mais de 2.481 (PESSANHA, 2008, p. 32), mas também pelo seu papel funcional, afinal, é a partir dele que o Presidente da República passa a ter atribuições legislativas próprias.

A primeira fonte formal atribuindo o decretos-lei ao Presidente da República veio com a Constituição de 1937. Neste interregno, é importante ressaltar que a Carta de 37, fundadora do Estado Novo, fora concebida por Francisco Campos em um contexto de crítica à "democracia de partidos" e influenciado pela teoria do Estado de Carl Schmitt", que, na visão de Campos, teria

$4 \quad$ Para duas visões sobre a influência de Carl Schmitt no pensamento de Francisco Campos, cfr: SANTOS, R. D. Francisco Campos e os fundamentos do constitucionalismo antiliberal no Brasil. Dados, v. 50, n. 2, p. 281-323, 2007. Disponível em: <http://www.scielo.br/scielo.php?script=sci_arttext\&pid=S0011$52582007000200003 \& \operatorname{lng}=$ en\&nrm=iso>. Acesso em 23 de maio de 2020 e PANAIT, I. "Democracia", "Autoridade" 
Cadernos de Estudos Sociais e Políticos, Rio de Janeiro, vol. 6, 2018.

cooptado a política nacional e o regime varguista surgiria como uma forma de dar densidade "[a]o Estado de consciência coletiva" (CAMPOS, 1941, p. 289).

Apesar do Congresso Nacional não ter sido aberto durante o período de vigência do texto constitucional de 1937, é interessante analisar o aspecto formal garantido ao Presidente através da figura do decreto-lei. Em um aspecto formal, o texto garantia ao Presidente ampla margem legislativa ao permitir que, por decreto-lei, sobretudo em razão dos limites decorrentes do uso do instrumento estavam amordaçados pelo fato de que a atividade parlamentar havia sido suspensa. Nesse sentido, afirmava o art. 180 da Carta de 37: "Enquanto não se reunir o Parlamento nacional, o Presidente da República terá o poder de expedir decretos-leis sobre todas as matérias da competência legislativa da União".

Com advento da Constituição de 1946, a figura do decreto-lei deixou de existir, inclusive, não havendo outra igual em uma possível reação à centralização de poder. Provisoriamente. A figura do decreto-lei voltou a surgir com a Constituição de 1967, três anos após o golpe militar, em uma faceta ainda mais expansionista. Logo após, a figura do decreto-lei é repetida na Constituição de 1969 com a mesma estrutura de 1967, simbolizando um relativo enraizamento desse instrumento como parte de uma forma de atuação direta do poder central em seara legislativa.

Para esse artigo, tenta-se compreender em que medida o papel dos decretos-lei permitiu uma forma de 'centralização' - ainda mais aguda - temática do poder executivo expondo isto em vários momentos-chave do contexto brasileiro.

\section{MEDIDAS PROVISÓRIAS}

As medidas provisórias mantiveram parte do espírito dos decretos-lei ao permitir que o gabinete da Presidência da República possua formas para induzir seus interesses dentro da arena pública, apesar de possuírem um escopo de atuação muito menor. Tal como no caso dos decretoslei, as medidas provisórias também têm sua natureza vinculada ao Presidente da República que as expede sob o binômio da "relevância" e da "urgência". Entretanto, as MPs precisam, necessariamente, ter sua análise submetida à apreciação do Congresso Nacional sob pena de não conversão em lei, isto é, perder o seu efeito no mundo fenomênico. Inclusive, é de se citar que o efeito de sua não discussão quando do término do prazo para a conversão ou não em lei é bastante significativo: a paralisia de toda a pauta legislativa do próprio Congresso Nacional.

e "Educação": A construção do pensamento político-jurídico de Francisco Campos e a Constituição de 1937. Dissertação (Mestrado em Ciências Sociais) - Pontifícia Universidade Católica do Rio de Janeiro, Rio de Janeiro, 2018. 
Cadernos de Estudos Sociais e Políticos, Rio de Janeiro, vol. 6, 2018.

Não obstante as novas limitações, o poder executivo federal, na figura do gabinete a Presidência da República, costuma utilizar com frequência as "MP's" independentemente dos períodos de crise política, mas para efeitos deste artigo, far-se-á um recorte para melhor contemplar os propósitos metodológicos aqui inseridos. Por crises políticas sob a vigência do período democrático, o artigo considerará: a crise no México de 1994, crise asiática de 1997, a crise russa de 1998, a crise cambial de 1999 e a crise argentina entre os períodos de 1999 e 2000, todas ocorridas durante o governo Fernando Henrique Cardoso (1994-2002).

\section{VETOS PRESIDENCIAIS}

Os vetos presidenciais são uma figura típica de controle político exercido pelo Presidente da República desde a “Constituição de 1891 pelo menos” (DALLARI, 2015, p. 27). No decorrer da história constitucional do Brasil, no entanto, pode-se observar uma certa modulação no escopo de revisão do veto do Presidente pelo poder Executivo. Na Constituição de 1946, por exemplo, para rejeitar um veto expedido pelo Presidente necessário seria reunir o apoio de $2 / 3$ do Congresso (Senado + Câmara dos Deputados), já na Constituição de 1988, por exemplo, é necessário a maioria absoluta dos deputados e senadores ${ }^{5}$.

De todo modo, a figura do veto presidencial continua sendo fundamental para o jogo político entre Legislativo e Executivo. Ao garantir ao Presidente a possibilidade de controlar, ainda que indiretamente, a própria atividade produtiva parlamentar, o veto tem sua função como poder de agenda. Por ser ferramenta política importante na correlação de forças entre os poderes, o veto presidencial deve ser analisado com atenção.

Neste artigo, procuraremos compreender a dinâmica dos vetos presidenciais dados pela Presidenta Dilma quando do seu governo (2010-2016) especialmente em contraste a um momento de crise política em particular deste governo.

\section{CRISES POLÍTICO-ECONÔMICAS E A GESTÃO DAS CRISES PELO EXECUTIVO: O DESPERTAR DO GIGANTE}

\footnotetext{
5 BRASIL. República Federativa do Brasil. Constituição da República Federativa do Brasil. “Art. \ 4 O veto será apreciado em sessão conjunta, dentro de trinta dias a contar de seu recebimento, só podendo ser rejeitado pelo voto da maioria absoluta dos Deputados e Senadores."
} 
Cadernos de Estudos Sociais e Políticos, Rio de Janeiro, vol. 6, 2018.

Pensar um instrumento político como uma forma de gerir uma crise pode ser uma maneira interessante de se observar o campo de atuação do Executivo. Sejam em crises ambientais, crises de segurança pública ou mesmos crises propriamente econômicas, em todos os momentos a reação oficial é de preservação das instituições mais básicas do aparelho estatal lançando mão de novas estratégias políticas para perceber como uma agenda política é controlada.

Para executar a gestão dessas crises todas, o Poder executivo, seja federal, estadual ou municipal, tem a disposição um ferramental, formal ou informal, à sua disposição. Isso pode não significar o mero uso da ferramenta puramente para o cumprimento da finalidade a ela incumbida, mas também para conduzir uma agenda de interesses próprias, ainda que à revelia dos outros poderes. A fome do gigante nada mais é que a vontade de comer boa parte do bolo, sem se importar com o apetite dos outros.

\section{A POLÍTICA POR DECRETO-LEI DO ESTADO NOVO}

O regime de exceção historicamente conhecido como "Estado Novo", instaurado por Getúlio Vargas, perdurou entre os anos de 1937 até 1946. Do ponto de vista político-institucional, o regime caracterizou-se, sobretudo, por ser uma autocracia com forte centralização de poder na figura do Presidente da República. Um contraste dessa centralização está na edição profícua de vários decretos-lei visando empreender a construção de uma nova estrutura de Estado.

A título de exemplo, os decretos-lei no 5.684 (Companhia Nacional de Álcalis), 4.352, de 1 de junho de 1942, (Companhia Vale do Rio Doce), 1.186, de 3 de abril de 1939 (Instituto de Resseguros do Brasil), decreto-lei no 3.306, de 24 de maio de 1941 (Companhia Hidrelétrica do São Francisco, o Conselho Federal do Comércio Exterior, a lei da sociedade anônima e a Estrada de Ferro Central do Brasil), 2.162, de $1^{\circ}$ de maio de 1940 (institui o salário mínimo), 5.452, de $1^{\circ}$ de maio de 1943 (institui a Consolidação das Leis Trabalhistas) apontam para um dirigismo estatal em quase todos os setores da economia. Isso considerando somente o aspecto econômico das medidas do Estado Novo. Outros decretos-lei foram impostos, tais como a instalação de polícia política dedicada à censura (decreto-lei no 1.915 , de 27 de dezembro de 1939).

Com relação à máquina pública, o decreto-lei no 519, de 30 de julho de 1938, tem sua importância por ser uma tentativa de organização do Estado a partir da adoção do critério dos concursos públicos para a admissão de servidores públicos de carreira ante às ameaças à figura viva do patrimonialismo da época.

O cenário de exceção colaborou com a possibilidade de imposição de uma agenda monolítica por parte do Executivo sobre os outros poderes. Por outro lado, isso não descarta o 
Cadernos de Estudos Sociais e Políticos, Rio de Janeiro, vol. 6, 2018.

uso desenfreado dos decretos-lei para a promoção dessa agenda constatando uma preocupação institucional do Presidente promovê-la a partir dos instrumentos oficiais.

\section{O GOVERNO JANGO E O DECRETO DA REFORMA AGRÁRIA}

O período democrático posterior ao Estado Novo durou 18 anos. Compreendido entre 1946 até 1964, o Brasil esteve sob à égide da Constituição de 1946, que não retirou dos poderes do Presidente da República a possibilidade de decreto-lei. De todo modo, no tocante ao período de governo de João Goulart (1961-1964), o país sofreu elevada instabilidade político-econômica em decorrência de grande desconfiança fruto da conexão histórica entre o presidente e Getúlio Vargas.

Uma das medidas visando contingenciar parte dessa crise político-econômica e visando atingir parte do problema de desigualdade na distribuição de terras, o Presidente João Goulart expede o decreto n $n^{\circ} 55.700$, em 13 de março de 1964 ("Desapropriação para a reforma agrária"). A justificativa para o decreto seria "resolver o problema rural, restabelecendo a paz em áreas marcadas por uma crescente mobilização social, uma reforma agrária, na visão que se afirmou, seria capaz de colocar o país nos trilhos da industrialização e do desenvolvimento econômico" "

O objeto do decreto "declarava de interesse social para fins de desapropriação, as áreas rurais compreendidas em um raio de $10 \mathrm{~km}$ dos eixos de rodovias e ferrovias federais, bem como as terras beneficiadas ou recuperadas por investimentos exclusivos da União em obras de irrigação, drenagem e açudagem" (CUNHA FILHO, 2007, p. 11). À época, diversos setores da sociedade civil reagiram ao decreto pela insinuação de que seria uma reforma agrária socialista.

De fato, em meio a um Congresso reativo às pretensões a figura de João Goulart, sobretudo, pelos acenos diplomáticos dados à China e à Cuba, o Presidente lança mão do decreto de desapropriação em uma tentativa de governo sofrendo, dias depois, um golpe de Estado.

\section{O GOVERNO FHC E A PIRACEMA DAS MEDIDAS PROVISÓRIAS}

Outro governo em meio às várias crises político-econômicas foi o governo Fernando Henrique (1994-2002). Em todas elas, o volume de medidas provisórias foi significativamente alto. Em média, o governo FHC editou cerca de uma nova medida provisória a cada dez dias?

\footnotetext{
6 GRYNSZPAN, M. A questão agrária no governo Jango. CPDOC - Centro de Pesquisa e Documentação de História Contemporânea do Brasil da Fundação Getúlio Vargas. Disponível em: $<$ http://cpdoc.fgv.br/producao/dossies/Jango/artigos/NaPresidenciaRepublica/A_questao_agraria_no_governo_J ango $>$ Aceso em 30 de maio.2018

BRASIL. Folha de São Paulo. "FHC edita uma nova MP a cada 10 dias de governo". Disponível em: $<<$ http://www1.folha.uol.com.br/fsp/brasil/fc280206.htm>> Acesso em 24 de maio, 2020.
} 
Cadernos de Estudos Sociais e Políticos, Rio de Janeiro, vol. 6, 2018.

Comparado ao governo de Michel Temer (2016-2018), a administração FHC foi a segunda mais ativa na condução da política através de medidas provisórias ${ }^{8}$

Do ponto de vista temático, as medidas provisórias expedidas pelo governo FH tentaram, em larga medida, controlar parte dos danos causados pelas crises econômicas ocorridas durante seu governo. Se observamos os dados coletados por Arias (2001), podemos notar uma forte predominância na agenda parlamentar advinda da agenda do presidente:

Os dados analisados por eles confirmam que a área de atuação do Congresso, ao longo da legislatura 1995-98, foi restringida pela agenda presidente: foram 648 propostas iniciadas pelo Executivo, aproximadamente $75 \%$ delas foram sobre temas ligados diretamente à economia, quase $17 \%$ propostas administrativas, e apenas $8 \%$ estavam relacionadas a temas políticos ou sociais. (ARIAS, 2001, p. 36)

Se por um lado as medidas provisórias serviram como instrumento às mãos do presidente para impor sua agenda, por outro lado, seu largo uso pelo Executivo significou um verdadeiro backlash do poder Legislativo. A partir da promulgação da emenda constitucional no 32, em 2001, as Casas legislativas impuseram uma verdadeira limitação material aos poderes do Presidente em expedir medidas provisórias. Abrucio e Couto (2003) explicam um dos possíveis motivos pelos quais a emenda constitucional $n^{\circ} 32$ foi pautada e posteriormente promulgada:

Tornara-se praxe desde 1988 o uso descomedido da prerrogativa de editar e, sobretudo, reeditar MPs por parte do Executivo. A interpretação dos imperativos constitucionais de "relevância e urgência" para a utilização desse instrumento normativo tornara-se demasiadamente flexível, fazendo-se sinônimo de "pressa", por um lado, e de "conveniência legislativa", por outro. A pressa dizia respeito à pouca disposição presidencial de aguardar os trâmites legislativos ordinários - ou mesmo em regime de urgência. A conveniência legislativa concernia ao acordo tácito estabelecido entre o Executivo e a maioria parlamentar que lhe desse sustentação, permitindo a reedição continuada de MPs em vez de sua apreciação, enquanto se ocupava de assuntos mais trabalhosos, como a tramitação de emendas constitucionais. (Abrucio e Couto, 2003, p.293)

A predominância do poder de agenda do Presidente, ao menos durante o governo FHC, parece ter sido tanta que gerou até mesmo um efeito de limitação reconhecido pelo Legislativo.

\section{UM OLHAR SOBRE OS VETOS DA PRESIDENTA DILMA ROUSSEFF}

\footnotetext{
8 BRASIL. Portal G1. "Desde FHC, Temer é o presidente que, em média, mais edita medidas provisórias". Disponível: $<<$ https://g1.globo.com/politica/noticia/desde-fhc-temer-e-o-presidente-que-em-media-mais-editamedidas-provisorias.ghtml $>>$. Acesso em 27 de maio de 2020.
} 
Cadernos de Estudos Sociais e Políticos, Rio de Janeiro, vol. 6, 2018.

O primeiro biênio do primeiro mandato do governo Dilma Rousseff (2010-2014) pode ser caracterizado por relativa paz social. Considerando a popularidade alta em decorrência dos bons índices de emprego formal e crescimento da renda, é possível supor que, durante esse período, em específico, a presidenta não enfrentou grandes crises políticas, apesar do rescaldo da crise econômica de 2008 ainda gerar impactos. A chave muda a partir de 2013, especificamente, a partir de junho de 2013. Neste mês em questão, com advento dos grandes atos públicos conhecidos como “jornadas de junho de 2013”, a presidenta vê sua popularidade derreter em meio a manifestações com pautas coletivas difusas.

Em uma espiral de aumento de impopularidade ${ }^{9}$, a presidenta passa a imprimir um ritmo acelerado em atividade legislativa. Só em 25/6/2013, dias após o maior ato público da história recente, a presidente apresentou 5 pactos e uma proposta de reforma na Constituinte ${ }^{10}$ visando cumprir parte dos anseios populares. Do mesmo modo, o ritmo de vetos presidenciais às medidas aprovadas no parlamento brasileiro se intensificou, tal como as sucessivas derrotas da presidenta.

Entre tantos vetos presidenciais em 6 anos de mandato, cita-se importantes para destacar o impacto deste instrumento na condução da agenda política: (i) o veto ao reajuste dos servidores públicos ligados ao poder judiciário; (ii) veto a “lei de royalties' do petróleo, posteriormente derrubado pelo Congresso Nacional.

No primeiro caso, a justificativa da presidenta era de que o reajuste a ser incorporado seria incompatível dados os "esforços necessários para o equilíbrio fiscal na gestão de recursos públicos" $"$. O contexto não poderia ser outro: a crise econômica de 2005. A retórica oficial do governo, naquela época, era de ajuste fiscal dado o aumento expressivo da dívida pública. O veto foi mantido pelo Congresso Nacional.

No segundo caso, um contraste é feito para realçar os limites dos vetos presidenciais quanto a possibilidade de um poder reativo do Congresso. No tocante a lei dos royalties do petróleo, a presidenta sofreu um revés importante, e talvez um dos sinais do descontrole político de seu governo que viria desembocar em seu posterior afastamento definitivo do cargo de Presidenta. Neste projeto de lei, a presidenta procurou vetar os dispositivos que permitiam a divisão dos royalties do petróleo para os Estados produtores, a chamada "partilha dos royalties". Não obteve

\footnotetext{
9 BRASIL. Folha de São Paulo. "Popularidade de Dilma cai 27 pontos após protestos". Disponível em: $<<$ http://www1.folha.uol.com.br/poder/2013/06/1303541-popularidade-de-dilma-cai-27-pontos-aposprotestos.shtml >> Acessado em 30.05.2018

10 BRASIL. Portal G1. "Dilma propõe 5 pactos e plebiscito para constituinte da reforma política". Disponível em: $\quad<$ http://g1.globo.com/politica/noticia/2013/06/dilma-propoe-5-pactos-e-plebiscito-para-constituinte-dareforma-politica.html $>>$ Acesso em 31 de maio de 2018.

11 BRASIL. Senado Federal da República Federativa do Brasil. Veto no 26/2015.
} 
Cadernos de Estudos Sociais e Políticos, Rio de Janeiro, vol. 6, 2018.

êxito e teve seus vetos derrubados pelo Congresso Nacional ${ }^{12}$ em uma das derrotas mais significativas do governo sinalizando para um enfraquecimento na condução da agenda da Presidência.

Tal como a medida provisória, o veto presidencial é um instrumento com suas particularidades e sua função na correlação de forças com o poder Legislativo. Seu uso pelo presidente pode significar uma maneira formal de controle da pauta legislativa aprovada, sobretudo, quando a pauta discorda da agenda da Presidência.

\section{GOVERNO TEMER: OS GRANDES IMPACTOS DE UM CURTO GOVERNO}

O jurista Michel Temer assumiu interinamente a presidência da República no fatídico dia $12 \backslash 06 \backslash 2016$ após a abertura do processo de impeachment em face da Presidenta Dilma Rousseff e, com o término no procedimento no Congresso Nacional, tomou posse em $31 \backslash 08 \backslash 2016$. O Governo Temer é marcado, do início ao fim, por uma forte desconfiança que culminou em baixos índices de popularidade que permearam toda a sua gestão.

Para além da crise de legitimidade, causada por uma visão de "continuidade" com o Governo Dilma e da crise de representação, estimulada por denunciantes do "golpe jurídico" (CHALOUB; LIMA, 2018, p. 203), estes componentes de uma crise política, Michel Temer ainda enfrentou uma grave crise econômica, proveniente dos efeitos dos julgados da operação Lava Jato e das crises arrastadas desde o anterior governo.

Aproveitando-se da sua sempre baixa popularidade, o Governo Temer buscou como solução das crises político-econômicas uma abertura às agendas do mercado, dando azo a um período reformista. Dentre o "pacote" de propostas reformistas, encontram-se: a) a PEC do Corte de gastos $^{13}$ (Novo Regime Fiscal), que vincula as despesas e investimentos públicos federais aos do regime orçamentário anterior, corrigidos somente pela inflação; b) A reforma trabalhista e a Lei da Terceirização; c) a elaboração da nova Base Nacional Comum Curricular e; d) a proposta de reforma da previdência social, liderada pelo economista Henrique Meirelles (então Ministro da

\footnotetext{
12 Brasil. Portal de Notícias UOL. "Congresso derruba vetos da presidente Dilma à lei dos royalties” Disponível em <<https://noticias.uol.com.br/politica/ultimas-noticias/2013/03/07/congresso-derruba-vetos-da-presidentedilma-a-lei-dos-royalties.htm $>>$. Acesso em 27 de maio de 2020.

13 Transformada na Emenda Constitucional nº 95, Cfr: BRASIL, Câmara dos Deputados. Trâmite da EC 95/2017. Disponível em:

$<<$ https://www.camara.leg.br/proposicoesWeb/fichadetramitacao?idProposicao=2088351 >>. Acesso em 23 de maio de 2020.
} 
Cadernos de Estudos Sociais e Políticos, Rio de Janeiro, vol. 6, 2018.

Fazenda), esta inviabilizada em razão da intervenção federa ${ }^{14}$ na segurança pública no Estado do Rio de Janeiro.

A correlação de forças do Executivo para com o Legislativo e a exposição da agenda do Governo durante o mandato de Temer se dava, sobretudo, pelas proposituras de emendas à Constituição (que prescinde da sanção e/ou veto do Presidente) e, sobretudo, pela edição de medidas provisórias: 142 em 31 meses de governo.

\section{GOVERNO BOLSONARO: PRESIDENCIALISMO DE CONFRONTAÇÃO?}

Ao menos a partir da década de 1980, os pesquisadores e pesquisadoras das ciências políticas passaram a se debruçar sobre os principais entraves institucionais do país. O cientista político Sérgio Abranches observou um padrão de governabilidade vigente à época de seus estudos e o definiu como "presidencialismo de coalizão"

\footnotetext{
Apenas uma característica, associada à experiência brasileira, ressalta como uma singularidade: o Brasil é o único país que, além de combinar a proporcionalidade, o multipartidarismo e o "presidencialismo imperial", organiza o Executivo com base em grandes coalizões. A esse traço peculiar da institucionalidade concreta brasileira chamarei, à falta de melhor nome, "presidencialismo de coalizão", distinguindo-o dos regimes da Áustria e da Finlândia (e a França gaullista), tecnicamente parlamentares, mas que poderiam ser denominados de "presidencialismo de gabinete" (uma não menos canhestra denominação, formada por analogia com o termo inglês cabinet government) (ABRANCHES, 1988, p. 21)
}

Desde então, o conceito de presidencialismo de coalizão tem servido como uma das principais chaves de interpretação para compreender também o funcionamento do poder de agenda do Executivo federal. Com relação ao governo do Presidente Jair Bolsonaro, esse ferramental aparece ainda interessante ao debate.

Uma das expectativas à época de sua eleição era de que ele pretendia acabar ${ }^{15} \mathrm{com}$ o "presidencialismo de coalizão". Considerando os primeiros 365 dias de mandato, o governo do Presidente Jair Bolsonaro, de fato, parece ter encontrado um outro padrão de governabilidade o que, segundo Sérgio Abranches, seria, na verdade, um "presidencialismo de confrontação".

Nesse sentido, o presidencialismo de confrontação, no caso, poderia se observar em alguns dados preliminares relativos ao primeiro ano de mandato do Presidente Bolsonaro, que sugerem uma relativa dificuldade em implementar sua agenda. Em termos de gestão de crise, - foco de análise deste artigo -, considerando o período ainda não encerrado de estado de emergência em

14 O art. $60, \$ 1^{\circ}$ da Constituição determina a impossibilidade de sua alteração/reforma enquanto estiver em vigência a intervenção federal.

15 TAVARES, Joelmir. Bolsonaro põe presidencialismo de coalizão à prova ao arriscar novo estilo. Folha de São Paulo. 24 nov. de 2018. 
Cadernos de Estudos Sociais e Políticos, Rio de Janeiro, vol. 6, 2018.

razão da pandemia de covid-19 os dados ainda são tímidos para avaliar a forma com que o Presidente lida com essa crise em particular.

\section{CONSIDERAÇÕES FINAIS}

Neste artigo, sugerimos uma leitura para compreender a reação do poder executivo frente às várias crises político-econômicas ocorridas no contexto brasileiro. Conforme observado em diferentes momentos históricos, considerando o período compreendido entre o Estado Novo e o governo de Jair Bolsonaro, o Presidente da República lançou mão do ferramental jurídico a sua disposição para lidar com as tais crises.

Do mesmo modo, sugeriu-se a hipótese de que poder executivo utiliza desses instrumentos para impor sua agenda de interesses em um movimento de 'poder de agenda'. As movimentações podem ser observadas desde o momento da expedição dos decretos-lei à época do Estado Novo até os vetos presidenciais do período democrático em uma tentativa de aproveitar uma janela de oportunidade política para garantir uma predominância temática.

Nesse sentido, ao compreendermos a forma com que o Poder executivo maneja seus instrumentos de agenda, sobretudo, em momentos de crise político-econômica, conseguimos verificar um determinado padrão de governabilidade.

\section{BIBLIOGRAFIA}

ARIAS, C. Um estudo sobre medidas provisórias no Brasil. Revista Mediações,. v. 6. n. 2. p. 29-53, 2001.

ABRANCHES, S. Presidencialismo de Coalizão: o dilema institucional brasileiro. Dados, vol. 31, n. 1, p. $5-14,1988$.

ABREU JUNIOR, D. A. Medidas provisórias: o poder quase absoluto. Brasília: Câmara dos Deputados, Coordenação de Publicações, 2002.

BEDRITICHUK, R. R. Da Popularidade ao Impeachment: Medidas provisórias, mudanças institucionais e a crise política no governo Dilma. Dissertação de Mestrado. Instituto de Ciência Política, Universidade de Brasília, Brasília, 2016.

CAMPOS, F. O Estado nacional: sua estructura, seu conteúdo ideológico. 3a edição -. Rio de Janeiro: José Olympio, 1941. 
Cadernos de Estudos Sociais e Políticos, Rio de Janeiro, vol. 6, 2018.

CHALOUB, J.; LIMA, P. L. Os juristas políticos e suas conviç̧ões: para uma anatomia do componente jurídico do golpe de 2016 no Brasil. Revista de Ciências Sociais, v. 49, n. 1, p. 202-252, 2018.

CUNHA FILHO, S. B. A Constituição de 1988 e a diminuição do poder estatal de desapropriar os imóveis rurais para fins de reforma agrária. Departamento de Direito, Pontifícia Universidade Católica do Rio de Janeiro, Rio de Janeiro, 2007.

DAHL, R. The concept of power, Behavioural Science, vol. 2, n. 3, p. 201-215. 1957.

DALLARI, Paulo Massi. O instituto do veto presidencial no constitucionalismo brasileiro contemporâneo. 2015. Tese de Doutorado. Universidade de São Paulo.

DINIZ, S. Interações entre os Poderes Executivo e Legislativo no Processo Decisório: Avaliando Sucesso e Fracasso Presidencial - Revista de Ciências Sociais, Vol. 48, n. 1, 2005, p. 333-369.

GUANDALINI JR., W.; CODATO, A. O Código Administrativo do Estado Novo: a distribuição jurídica do poder político na Ditadura. Estudos Históricos, v. 29, n. 58, p. 481-504, 2016. Disponível em: $<$ http://www.scielo.br/scielo.php?script=sci_arttext\&pid=S0103$21862016000200481 \& \operatorname{lng}=$ en\&nrm=iso $>$. Acesso em 23 de maio, 2018.

JACOBSEN, H. L. G. Interação estratégica entre os poderes executivo e legislativo: as medidas provisórias editadas nos mandatos de Lula e Dilma (2003-2014). Dissertação (Mestrado em Ciência Política). Programa de Pós-Graduação em Ciência Política. Instituto de Filosofia, Sociologia e Política, Universidade Federal de Pelotas, Pelotas, 2016.

MAINWARING, S; SHUGART, M. S., Presidentialism and democracy in Latin America. Cambridge: Cambridge University Press. 1997.

MENDES, Antonio Mira Marques "Subsídios para uma teoria das crises políticas". In: Anais do IV Congresso Spocom. Aveiro: Universidade de Aveiro, p. 765-774, 2005.

PANAIT, I. "Democracia", "Autoridade" e "Educação": A construção do pensamento político-jurídico de Francisco Campos e a Constituição de 1937. Dissertação (Mestrado em Ciências Sociais) - Departamento de Ciências Sociais, Pontifícia Universidade Católica do Rio de Janeiro, Rio de Janeiro, 2018.

PEREIRA, C.; MUELLER, B. Uma teoria da preponderância do Poder Executivo: o sistema de comissões no Legislativo brasileiro. Revista Brasileira de Ciências Sociais, vol.15, n.43, pp.45-67, 2000.

PERSON, C. M. Reframing Crisis Management. Academy of Management Review, vol. 23, n. 1, p. 5976, 1998.

RICCI, P.; TOMIO, F.. O poder da caneta: a Medida Provisória no processo legislativo estadual. Opinião Pública, v. 18, n. 2, p. 255-277, 2012. Disponível em: $<<$ http://www.scielo.br/scielo.php?script=sci_arttext\&pid=S0104-

62762012000200001\&lng=en\&nrm=iso >> . Acesso em: 23, maio, 2018.

SANTOS, F.. Patronagem e Poder de Agenda na Política Brasileira. Dados, v.40, n.3, 1997. Disponível em: $\quad<<$ http://www.scielo.br/scielo.php?script=sci_arttext\&pid=S001152581997000300007\&lng=en\&nrm=iso >>. Acesso em 23 maio, 2018. 
Cadernos de Estudos Sociais e Políticos, Rio de Janeiro, vol. 6, 2018.

SANTOS, R. D. Francisco Campos e os fundamentos do constitucionalismo antiliberal no Brasil. Dados, v. 50, n. 2, p. 281-323, 2007. Disponível em: $<<$ http://www.scielo.br/scielo.php?script=sci_arttext\&pid=S0011-

$52582007000200003 \& \operatorname{lng}=$ en\&nrm $=$ iso $>>$. Acesso em 23 de maio de 2020 